\title{
Programa Bolsa Família como estratégia de combate à pobreza em Dissertações e Teses no Brasil
}

\section{The Bolsa Família Program as a strategy to combat poverty in dissertations and theses in Brazil}

\author{
Viviam Rafaela Barbosa Pinheiro Freire* \\ Universidade Federal do Pará - UFPA, Belém, Pará, Brasil
}

\section{Simone Souza da Costa Silva**}

Universidade Federal do Pará - UFPA, Belém, Pará, Brasil

\author{
Lilia I êda Chaves Cavalcante*** \\ Universidade Federal do Pará - UFPA, Belém, Pará, Brasil
}

\section{Fernando Augusto Ramos Pontes****}

Universidade Federal do Pará - UFPA, Belém, Pará, Brasil

\begin{abstract}
RESUMO
Esta pesquisa objetivou mapear Dissertações e Teses sobre o Programa Bolsa Família (PBF) disponíveis no Banco de Teses da Capes. A busca e seleção resultaram em 166 trabalhos entre os anos de 2004-2009. Os resumos foram analisados e categorizados em: 1) Publicação de Dissertações e Teses por nível acadêmico e ano; 2) Área, palavras-chave e método das Dissertações e Teses; 3) Enfoque de investigação nas regiões do Brasil; e 4) Conteúdo temático por nível acadêmico. Observou-se que 75,9\% das pesquisas eram compostas de Dissertações de Mestrado acadêmico, sendo um tema de interesse para diversas áreas do Conhecimento. A maioria dos trabalhos $(81,3 \%)$ utilizou o enfoque empírico. O Nordeste foi a região brasileira mais investigada $(45,3 \%)$. Houve predominância $(33,6 \%)$ de pesquisas que não apontavam efeitos positivos ou negativos conclusivos do Programa Bolsa Família (PBF). Conclui-se que não há um consenso na literatura investigada sobre a consolidação do PBF como estratégia de combate à pobreza.
\end{abstract}

Palavras-chave: Desenvolvimento, PBF, Revisão.

\begin{abstract}
This research aimed to review dissertations and theses about Bolsa Família Program (BFP) available at Capes theses database. The search and selection resulted in 166 studies between the years 2004-2009. The abstracts were analyzed and categorized into: 1) Publication of dissertations and theses by academic level and year, 2) Field, keywords, and method of dissertations and theses, 3) Focus research in the regions of Brazil, and 4) Thematic content by academic level. It was observed that $75.9 \%$ of studies were of academic dissertations, being subject of interest to several fields of
\end{abstract}


knowledge. Most studies (81.3\%) used the empirical approach. The Northeast region of Brazil was the most investigated $(45.3 \%)$. There was predominance $(33.6 \%)$ of research that did not indicate conclusive positive or negative effects of the BFP. We conclude that there is no consensus in the literature investigated about the consolidation of the BFP as a strategy to combat poverty.

Keywords: Development, BFP, Review.

\section{I ntrodução}

O objetivo desta pesquisa é mapear as Dissertações e Teses sobre o Programa Bolsa Família (PBF) registradas no Banco de Teses, disponível no Portal da Coordenação de Aperfeiçoamento de Pessoal de Nível Superior (Capes). Trata-se de realizar uma caracterização dessa produção científica, apresentando o que tem sido investigado sobre as contribuições do PBF para a redução da pobreza na população brasileira.

Embora o PBF possa ser considerado recente, tem sido evidente o interesse científico pela identificação dos seus impactos nas condições de vida das famílias de crianças e adolescentes considerados em situação de vulnerabilidade social. No entanto, a diversidade de informações relativas a este e outros temas revela a necessidade de sínteses organizadoras que facilitem o acesso e a visualização do conhecimento proveniente de múltiplas fontes. Provavelmente, por isso, tem crescido o número de revisões sistemáticas que reúnem, organizam e sintetizam resultados de múltiplos estudos (COOK, MULROW \& HAYNES, 1997).

As revisões sistemáticas evidenciam e organizam os produtos, intervenções e informações científicas, tendo como principais características as fontes de busca abrangentes, seleção dos estudos primários sob critérios aplicados uniformemente e avaliação criteriosa da amostra (LOPES \& FRACOLLI, 2008). Neste sentido, Teses e Dissertações podem se constituir em importante fonte para identificação e comparação dos achados científicos sobre o tema em dada área do conhecimento.

Pesquisas em programas de pós-graduação se mostram relevantes sob vários aspectos, sendo um deles o fato de servirem como material de referência para outros tipos de publicação. De acordo com Canen, Arbache e Franco (2001), grande parte da produção acadêmico-científica representa a fonte inicial para artigos e capítulos de livros, constituindo-se em produção de Conhecimento geradora de novas investigações.

Para Campomar (1991), a necessidade da apresentação de Dissertação ou Tese para a obtenção de um título acadêmico é reconhecida como valiosa em razão de sua finalidade: realizar treinamento de pesquisadores e possibilitar Conhecimento novo em 
determinada área. Para este autor, trabalhos que envolvem pesquisa de campo têm recebido especial incentivo nos últimos anos, sobretudo devido o reduzido número de pesquisas que consigam compreender as transformações que envolvem os mecanismos atuais de gestão das políticas de combate às formas mais graves da pobreza no país.

Os Conhecimentos acumulados sobre a sociedade brasileira atual, segundo Reis e Shwartzman (2004), mostram que, embora o crescimento econômico alcançado nos últimos anos tenha colocado de vez o Brasil entre os países com economia aquecida e em alta no cenário internacional, existem milhões de pessoas excluídas de seus benefícios diretos e indiretos, assim como dos serviços oferecidos pelo governo aos cidadãos. Este fato revela a existência de um elevado nível de desigualdade social, expondo uma grande parcela da população à condição de vulnerabilidade.

Segundo o Instituto Brasileiro de Geografia e Estatística (IBGE), metade das famílias brasileiras vivia com menos de $\mathrm{R} \$ 415$ em 2008, o equivalente ao valor de um salário mínimo no mesmo ano. Além disso, a distribuição de renda no país continua bastante desigual, como demonstram os valores do rendimento mediano no Nordeste e no Sudeste: R\$ 250 contra R\$500, respectivamente. Assim, verificase que entre os menos favorecidos, a desigualdade econômica é resistentemente alta, a pobreza é alarmante, e a escolaridade e o desempenho escolar médios são muito baixos (KERSTENETZKY, 2009).

Este elevado índice de pobreza representa um risco para o desenvolvimento de crianças e adolescentes, já que se trata de um fator que não se traduz apenas na escassez de renda, mas também em insuficiência de desenvolvimento humano. A pobreza, portanto, marca as pessoas e suas relações, sendo considerada uma característica contextual dos indivíduos, como analisa Bronfenbrenner (1996). Nesses termos, compreender as condições contextuais em que famílias e crianças se desenvolvem passa necessariamente pelo Conhecimento das demandas dos que vivem em condições de pobreza.

Tal pressuposto permeia recentes estudos em desenvolvimento humano, onde, na perspectiva de Bronfenbrenner, o indivíduo e seu contexto são vistos de forma indissociável (CECCONELLO \& KOLLER, 2003; SIQUEIRA \& DELL'AGLIO, 2007; BARRETO, BUCHERMALUSCHKE, ALMEIDA \& DESOUZA, 2009). Nesse sentido, o contexto interfere no desenvolvimento, na medida em que as particularidades da pessoa e do ambiente interagem reciprocamente, produzindo constância e mudança nas características da pessoa e no curso de sua vida (BRONFENBRENNER, 1996).

O ambiente mais imediato, denominado de microssistema é constituído por papéis, atividades e relações face a face que são 
estabelecidas pela pessoa em desenvolvimento ao longo do tempo. Este ambiente também estabelece uma interação dinâmica e recíproca com contextos mais remotos, como é o caso do macrossistema, um contexto mais abrangente por envolver os sistemas de valores e crenças que se mantêm consistentes nos diferentes ambientes que são vivenciados e assimilados no decorrer do processo de desenvolvimento.

O macrossistema, segundo Barreto e cols. (2009), tem como alguns representantes as macroinstituições, como os Governos Federal, Estadual e Municipal, que exercem influência preponderante na pessoa, interferindo nas interações de todos os níveis ambientais e setores da vida social (trabalho, habitação, assistência social, entre outros). Suas políticas públicas refletem nos padrões reais e potenciais das inter-relações das pessoas e na organização da sociedade.

Pode-se considerar, nesse sentido, que os programas de transferência de renda, em especial o Programa Bolsa Família, representam ações do macrossistema geradoras de mudanças imediatas e de longo prazo nos grupos familiares e no desenvolvimento de crianças e adolescentes. O impacto na família ocorre quando os pais são incentivados pelo PBF a exercerem funções vitais que garantam o desenvolvimento dos filhos, como o acesso a saúde e a educação.

Assim, o governo federal lança mão do Programa Bolsa Família como estratégia de redução dos índices de pobreza que interferem no desenvolvimento nacional. Dentre seus objetivos, segundo informações da Caixa Econômica Federal (2011), destaca-se: combater a fome, combater a pobreza e outras formas de privação das famílias; promover o acesso à rede de serviços públicos, em especial, saúde, educação, segurança alimentar e assistência social; e criar possibilidades de emancipação sustentada dos grupos familiares. Ao ser criado pelo Decreto no 5.209 que regulamenta a Lei no 10.836, de 9 de janeiro de 2004, o PBF se instituiu da unificação de programas sociais pré-existentes: Bolsa Escola, Bolsa Alimentação, Vale Gás e Cartão Alimentação. Sua estrutura se destaca especialmente em dois eixos: transferência de renda, a fim de promover o alívio imediato da pobreza; e condicionalidades, que reforçam o acesso a direitos sociais básicos na tentativa de romper o ciclo intergeracional da pobreza.

São elegíveis ao PBF as famílias que se encontram em situação de extrema pobreza ou situação de pobreza. O benefício cedido pode ser do tipo básico e variável. Além disso, famílias que tenham adolescentes entre 16 e 17 anos freqüentando a escola recebem o benefício variável vinculado ao adolescente (Ministério do Desenvolvimento Social e Combate à Fome, 2010). 
Em contrapartida, o pagamento dos benefícios depende do cumprimento das condicionalidades, compromissos assumidos tanto pelas famílias beneficiárias do PBF quanto pelo Poder Público para ampliar o acesso aos direitos sociais básicos. Nesse sentido, tais exigências são válidas para as diferentes ações que compreendem o PBF, como as referentes à saúde, educação e assistência social.

$\mathrm{Na}$ área de saúde, as famílias beneficiárias assumem o compromisso de acompanhar o cartão de vacinação, o crescimento e desenvolvimento das crianças menores de 7 anos. As mulheres na faixa de 14 a 44 anos também precisam fazer o acompanhamento e, se gestantes ou nutrizes, devem realizar o pré-natal e 0 acompanhamento da sua saúde e do bebê.

$\mathrm{Na}$ educação, todas as crianças e adolescentes entre 6 e 15 anos necessitam estar matriculados e com frequência escolar mensal mínima de $85 \%$ da carga horária. Já os adolescentes entre 16 e 17 anos, também regularmente matriculados, devem ter frequência escolar de 75\%, no mínimo.

$\mathrm{Na}$ área de assistência social, diversas atividades são propostas para as famílias beneficiadas. Por exemplo, crianças e adolescentes com até 15 anos em risco ou retiradas do trabalho infantil pelo Programa de Erradicação do Trabalho Infantil (PETI), precisam participar dos Serviços de Convivência e Fortalecimento de Vínculos (SCFV) e obter freqüência escolar mínima de $85 \%$ da carga horária mensal.

Segundo a legislação e os documentos oficiais do Programa, as condicionalidades se justificam pela possibilidade de acesso e inserção da população pobre nos serviços sociais básicos, contribuindo para a independência das famílias beneficiárias. No entanto, sua imposição por parte do Poder Público tem sido muito criticada. Vários autores defendem que a um direito não se deve impor contrapartidas ou exigências, uma vez que a condição de pessoa deve ser o requisito único para a titularidade de direitos (BURLANDY, MONNERAT, SCHOTTZ \& MAGALHÃES, 2007; KERSTENETZKY, 2009; ZIMMERMANN, 2006). Outros afirmam que as condicionalidades exigem das famílias algo que já é determinado legalmente, portanto não há intrusividade na vida privada para além do que já determina a lei (MEDEIROS, BRITTOO E SOARES, 2007).

É importante destacar que o PBF como estratégia do governo federal de combater a pobreza envolve três dimensões fundamentais (PIRES, 2008): transferir renda diretamente aos mais pobres; fortalecer 0 direito de acesso das famílias pobres aos serviços de educação e saúde; promover a integração entre o Bolsa Família e as outras políticas públicas, seja no nível federal, estadual e municipal. Estas dimensões possuem alcance diferenciado no tempo, sendo a primeira de curto, a segunda de médio e a terceira de longo prazo.

Em suma, o Programa Bolsa Família beneficia a unidade familiar por meio de metas que vão além do combate à pobreza, já que 
demandam mudanças microssistêmicas que repercutem no desenvolvimento de crianças e adolescentes, como nos aspectos físicos, cognitivos e sócio-afetivos. Embora seja um programa recente, é grande o interesse por avaliações que permitam estimar a eficácia do PBF em atingir os objetivos a que se propõe formalmente. Tal Conhecimento, além de evidenciar a melhoria das condições de vida dos beneficiários, é essencial para aferir a adequação da abrangência e dos recursos despendidos (Oliveira, 2006; Scheeffer \& Johnson, 2008).

Em função do acesso a um grande contingente de informações, entende-se que a revisão sistemática da literatura sobre o tema tem muito a contribuir nesse debate que é nacional, mas incorpora necessariamente cenários regionais. Assim, este artigo pretende colaborar com a avaliação, focalizando num aspecto que considera fundamental: o mapeamento de Dissertações e Teses sobre o Programa Bolsa Família. Com isso, busca-se verificar o perfil da produção científica sobre o programa e indicar como tais estudos vem reconhecendo e interpretando os impactos na população beneficiária.

\section{Método}

A pesquisa procedeu à caracterização dos resumos das Dissertações e Teses publicadas no Banco de Teses da CAPES. Esta fonte de dados é integrante do Portal de Periódicos, uma biblioteca virtual que reúne e disponibiliza a produção científica nacional e internacional a instituições de ensino e pesquisa no Brasil.

\subsection{Procedimentos de busca e análise das Dissertações e Teses.}

A busca no banco de Teses da Capes ocorreu através do termo "Bolsa Família". Além das pesquisas de Doutorado, foram selecionados trabalhos de Mestrado de dois tipos: acadêmico e profissionalizante, no período de 2004 a 2009, que corresponde à fase de implantação do Programa Bolsa Família. Ao todo, foram localizados 166 títulos, após a exclusão de um registro duplicado.

A análise dos títulos e resumos das Dissertações e Teses foi feita por três juízes separadamente, ficando os dados alocados em quatro categorias abrangentes, baseadas em Oliveira, Siqueira, Dell'Aglio e Lopes (2008): 1) Publicação de Dissertações e Teses por nível acadêmico e ano; 2) Área, palavras-chave e método das Dissertações e Teses; 3) Enfoque de investigação nas regiões do Brasil; e 4) Conteúdo temático por nível acadêmico 


\section{Resultados e discussões}

\subsection{Publicações de Dissertações e Teses por nível acadêmico e ano}

Esta categoria refere-se ao levantamento de publicações por nível acadêmico e ano. Dentre os 166 registros, verificou-se que 75,9\% eram compostas de Dissertações de Mestrado acadêmico, tendo os níveis de Doutorado e Mestrado profissionalizante menor representatividade, com $9,0 \%$ e $15,1 \%$, respectivamente. O primeiro trabalho foi publicado em 2004 em nível de Mestrado Acadêmico. Pesquisas em nível de Doutorado foram publicadas a partir de 2005, enquanto que as de Mestrado profissionalizante foram encontradas a partir de 2007. (Figura 1)

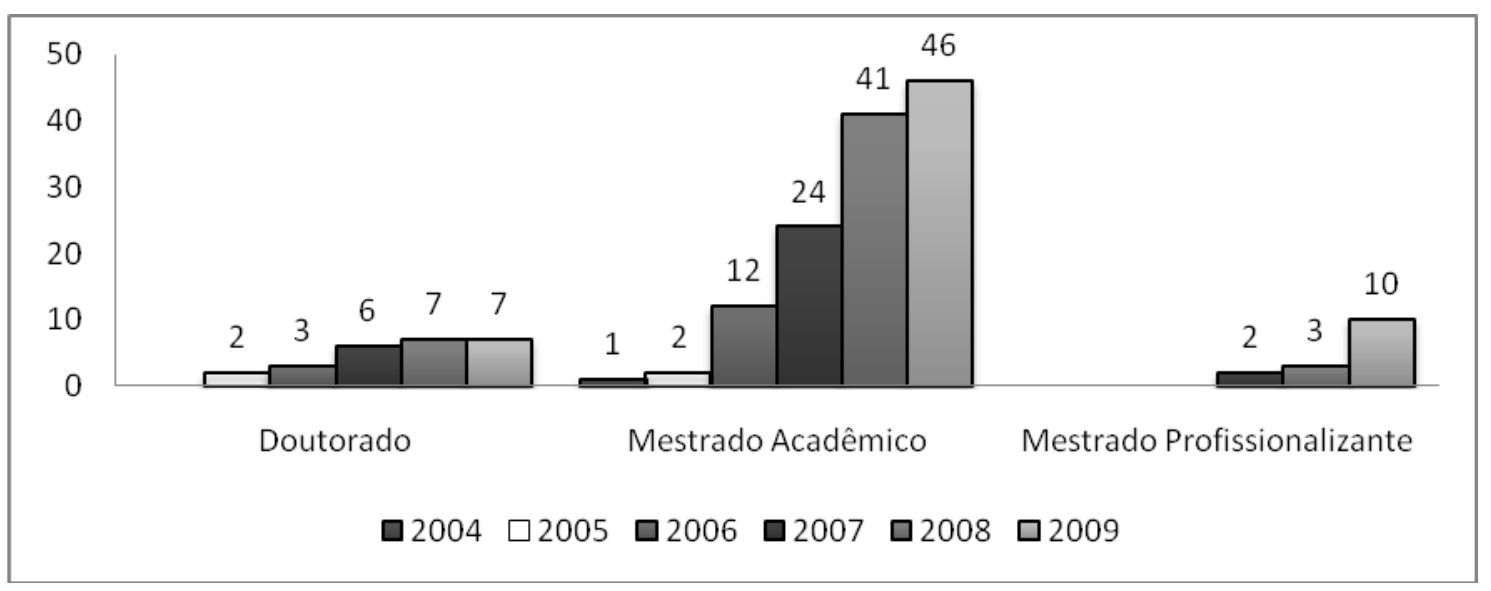

Figura 1: Publicação de Dissertações e Teses por nível acadêmico e ano.

Em todos os níveis acadêmicos verificou-se a tendência de crescimento em número de estudos sobre o tema, com destaque para os anos de 2007 e 2008. Vale ressaltar que, este período, corresponde ao início do segundo mandato do presidente Lula, cujo Plano de Governo (2007-2010) estabelece a manutenção do Bolsa Família como primeira frente de combate à fome, à pobreza e enfrentamento da desigualdade social.

Coerentemente com os achados deste estudo, Ferreira (2010) indica que um maior adensamento de trabalhos sobre o Programa Bolsa Família ocorreu nos anos de 2007 e 2008. Para a autora, tal resultado está associado ao clima político criado em torno do encerramento do primeiro mandato do Governo Lula e as disputas eleitorais de 2006. Complementarmente, de acordo com Lourenço (2006), este período refletia conquistas bastante expressivas alcançadas nos anos recentes como a desinflação, o equilíbrio nas contas externas, além do ambiente externo adequado, delineando um fortalecimento da estabilidade econômica. 


\section{2 Áreas, palavras-chave e método das Dissertações e Teses}

Esta categoria diz respeito ao levantamento da produção de acordo com a área de Conhecimento, palavras-chave e aspectos do método, a saber: natureza da pesquisa, forma de abordagem do problema, procedimentos técnicos da pesquisa e aspectos gerais dos participantes. De acordo com a tabela 1, diversas áreas de Conhecimento estão engajadas em pesquisas sobre o Programa Bolsa Família, dentre as que prevaleceram, Serviço Social e Economia tiveram maior destaque $(21,3 \%)$, enquanto que Direito $(4,1 \%)$ e Psicologia Social $(2,5 \%)$ foram menos representativos.

Tabela 1

Pesquisas publicadas por área de Conhecimento

\begin{tabular}{lcc}
\hline Área de Conhecimento & $\begin{array}{c}\text { Pesquisas } \\
\text { Publicadas }\end{array}$ & $\%$ \\
\hline Serviço Social & 26 & 21,3 \\
Economia & 26 & 21,3 \\
Nutrição e Saúde & 19 & 15,6 \\
Política Social & 16 & 13,1 \\
Educação & 12 & 9,8 \\
Administração & 8 & 6,6 \\
Sociologia & 7 & 5,7 \\
Direito & 5 & 4,1 \\
Psicologia Social & 3 & 2,5 \\
\hline Total & 122 & 100 \\
\hline
\end{tabular}

A diversidade de áreas de Conhecimento engajadas no estudo do PBF é bastante benéfica para todos os agentes envolvidos, em especial beneficiários e gestores. Tal benefício se justifica no fato de haver a construção de um corpo de Conhecimento multidisciplinar, abrangendo aspectos sociais, econômicos e políticos da gestão do programa.

Em relação às palavras-chave, observou-se que a mais recorrente, Bolsa Família, foi acompanhada de termos diversos, sendo os mais frequentes Política Social, Política Pública e Pobreza. Uma sínTese dos termos verificados pode ser visualizada na figura 2, cuja apresentação está subdividida pelas áreas de Conhecimento correspondentes às condicionalidades do programa, isto é, Serviço Social, Direito, Economia, Educação e Saúde. 


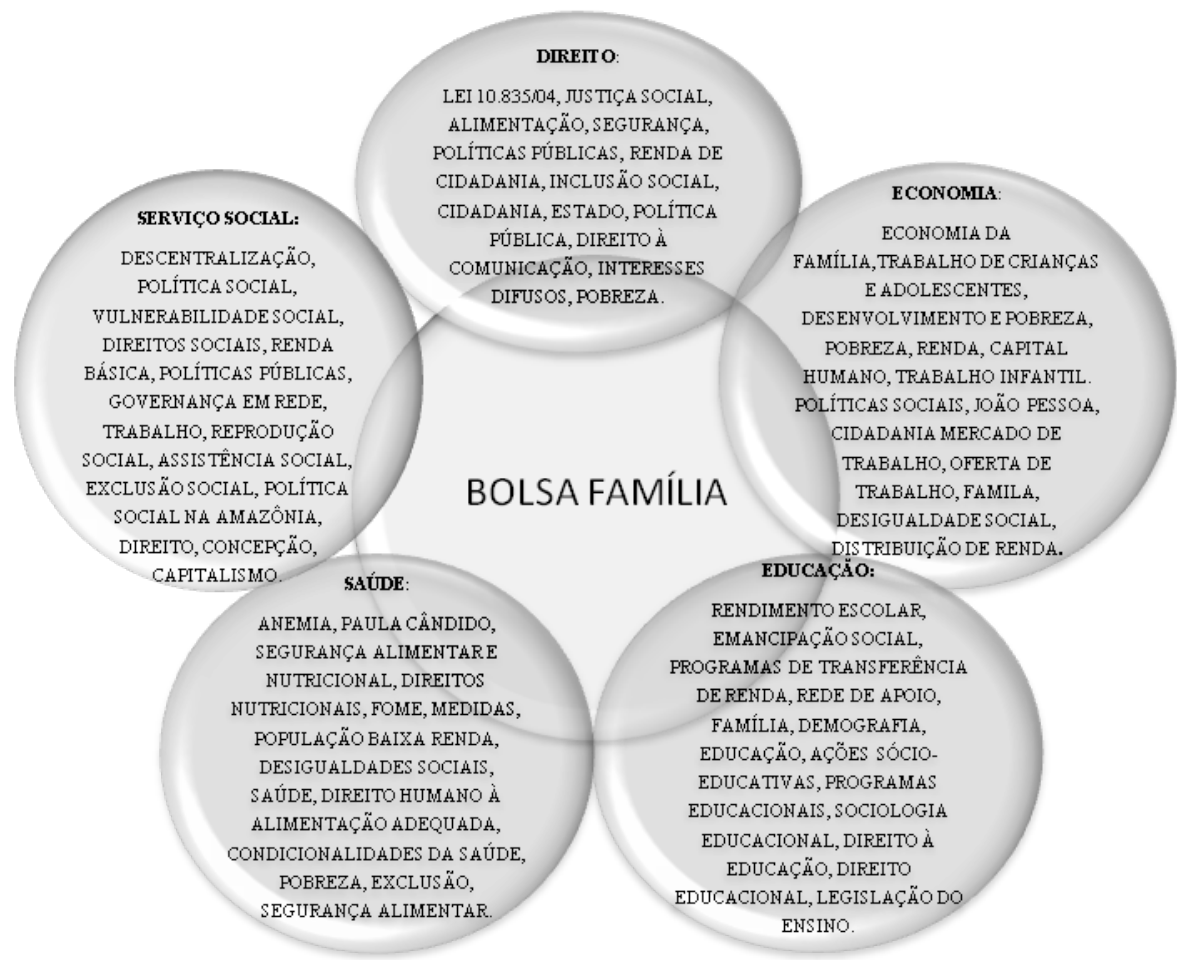

Figura 2. Exemplos de palavras chaves por área de Conhecimento.

Considerando a área de Serviço Social, pode-se citar como exemplos de palavras chaves: Descentralização, Política Social e Reprodução Social. $\mathrm{Na}$ área de Direito: Justiça Social, Políticas Públicas e Cidadania. Na área de Economia: Economia da Família, Distribuição de Renda e Desigualdade Social. Na área da Saúde: Segurança Alimentar, Fome e Direitos Nutricionais. Na área de Educação: Rendimento Escolar, Ações Sócio-Educativas e Programas Educacionais.

Por se tratar de um Programa que enseja pesquisas em diversas áreas do Conhecimento e visando a produtividade na busca de informações, alerta-se para que uma palavra-chave torne-se um descritor integrante de índices nacionais e internacionais. Desta forma o termo passa por um rígido controle de sinônimos, significado e importância na árvore de um determinado assunto, melhorando a condução e eficiência das buscas. (BRANDAU, MONTEIRO \& BRAILE, 2005).

Quanto à natureza da pesquisa, a maioria dos trabalhos $(81,3 \%)$ apresentou um enfoque empírico. Mas também verificou-se, em menor escala, a presença de obras teórico-empíricas $(0,6 \%)$ e as exclusivamente teóricas $(3,6 \%)$. Em cerca de $14,5 \%$ dos trabalhos não foi possível identificar, nos resumos, a natureza da pesquisa. Em $51,8 \%$ dos trabalhos empíricos consultados foi identificada a forma de abordagem do problema, com predominância da abordagem qualitativa $(22,9 \%)$. Os outros dois tipos de abordagens analisadas, 
quantitativo e quanti-qualitativo, obtiveram frequências semelhantes, com $14,8 \%$ e $14,1 \%$, respectivamente.

Em se tratando de um programa focalizado na população mais vulnerável socialmente, a predominância de pesquisas com abordagem qualitativa pode estar indicando uma preocupação por parte dos pesquisadores em conhecer mais profundamente dados que a pesquisa quantitativa não alcança. Apesar desse esforço, vários autores observam que os estudos qualitativos têm produzido pouco impacto na prática, com sua subutilização na formulação de políticas públicas (MATHEUS, 2009; THORNE, JENSEN, KEARNEY, NOBLIT, SANDELOWSKI, 2004).

Quanto aos procedimentos técnicos da pesquisa, somente em $27,1 \%$ das obras os divulgaram nos resumos, sendo possível classificá-los em Documental $(57,9 \%)$, Estudo de Caso $(26,5 \%)$ e Bibliográfica $(15,6 \%)$. Foi freqüente, porém, a identificação de pesquisas que combinaram tais procedimentos, de acordo com os objetivos a que se propõem. No que se refere aos participantes, as pesquisas evidenciaram características diversas, prevalecendo as que foram classificadas a partir de cinco grupos: família, gestores, mulheres, documentos oficiais e beneficiários do Programa Bolsa Família. Este último envolvia exclusivamente crianças, adolescentes ou homens adultos (figura 3 ).

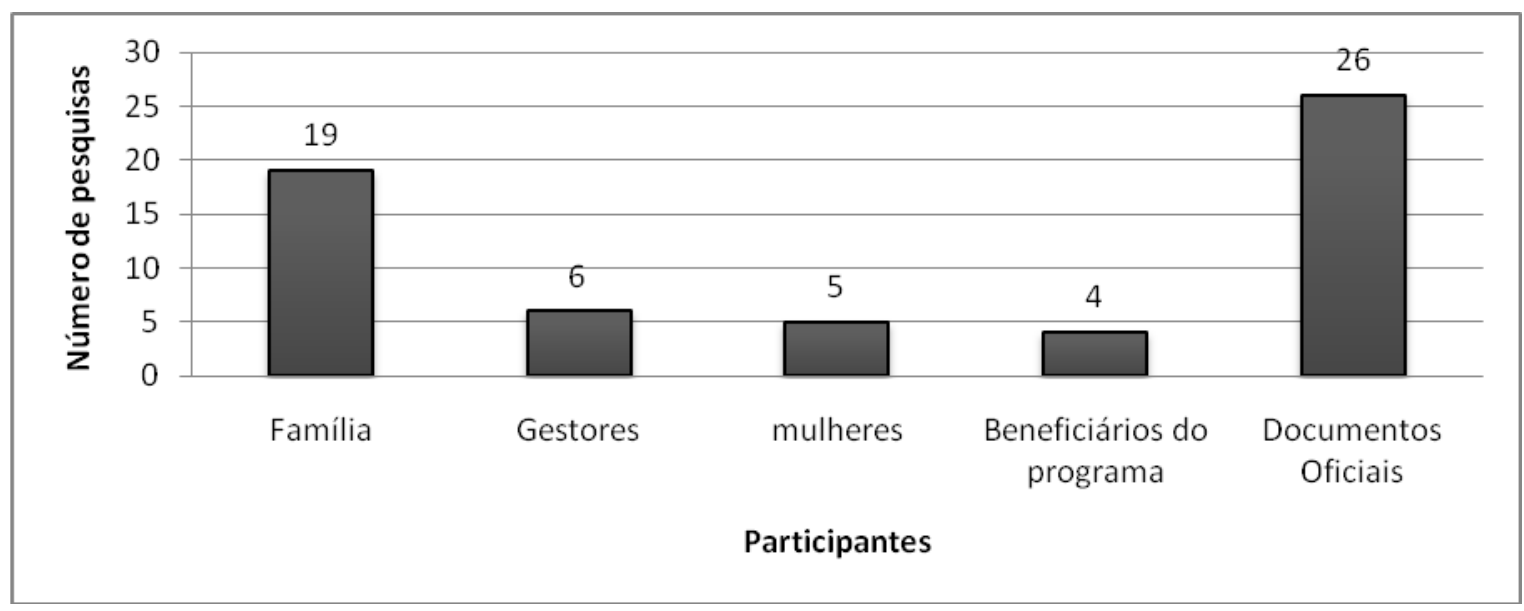

Figura 3. Levantamento de pesquisas por participantes. $(n=166)$

Dentre os trabalhos que mencionaram a amostra, a figura 3 ilustra a prevalência de documentos oficiais, compostos, principalmente, por dados do Instituto Brasileiro de Geografia e Estatística (IBGE), Pesquisa Nacional por Amostra de Domicílios (PNAD), Programa das Nações Unidas para o Desenvolvimento (PNUD), Ministério do desenvolvimento Social e Combate à fome (MDS) e Instituto de Pesquisa Econômica Aplicada (IPEA). Em alguns casos, os trabalhos divulgados por estas fontes se reportavam ao universo empírico das famílias e também de beneficiários do PBF, enquanto que, em outros, 
os dados coletados foram tratados e submetidos a testes estatísticos permitindo conclusões mais consistentes do ponto de vista científico.

A elevada freqüência do uso de documentos oficiais como fonte de dados provavelmente deve-se ao fato dos primeiros estudos sobre o PBF e seu impacto sobre a condição de vida dos brasileiros terem sido realizados pelo próprio governo, como mecanismos de avaliação das políticas públicas pelas agências estatais. Depois a academia foi chamada a dar conta dessa realidade que é relativamente nova. Vale ressaltar que a eleição de documentos nem sempre ocorreu de forma exclusiva, estando associada a outros tipos de participantes, como as famílias. A emancipação das famílias beneficiárias é um dos objetivos do Programa Bolsa Família. Esta pode ser a razão do grande interesse das pesquisas também adotarem majoritariamente este microssistema como contexto de pesquisa.

\subsection{Enfoques de investigação nas regiões do Brasil}

Esta categoria refere-se ao foco de investigação elucidado nos objetivos dos resumos empíricos analisados, considerando as particularidades regionais brasileiras. Objetivou-se, com esta análise, verificar quais os alvos de investimento do Programa Bolsa Família foram pesquisados nas diferentes regiões.

No Nordeste, foram realizados $45,3 \%$ trabalhos, sendo a região mais investigada dentre a amostra deste estudo. Quanto aos enfoques de investigação pode-se citar, entre outros, trabalho infantil, qualidade de vida, emprego, renda, cidadania, segurança alimentar e redução da evasão escolar. O estado do Ceará foi o mais pesquisado, com 12 publicações. O interesse científico por esta região talvez se deva ao fato do Nordeste deter o maior número de famílias consideradas de baixa renda no país, tanto que, em 2008, isso representava cerca de $42,2 \%$ dos seus habitantes vivendo em condições de pobreza (INSTITUTO DE PESQUISA ECONÔMICA APLICADA, 2007).

$\mathrm{Na}$ região Sudeste foram realizadas $27,9 \%$ das pesquisas, com destaque para os estados de Minas Gerais e Rio de Janeiro que apresentaram 11 e 10 trabalhos, respectivamente. Como exemplo de alvos de pesquisa nesta região pode-se citar: promoção à saúde, cidadania, antropometria (permite avaliar o estado nutricional de um indivíduo), desenvolvimento, inclusão social e condicionalidades de saúde.

A região Sul foi analisada em $15,1 \%$ das pesquisas, cujo enfoque envolvia, entre outros, rendimento escolar, condicionalidades e desenvolvimento econômico e social. A região Norte foi contemplada com 7,0\% das pesquisas, tendo como principais alvos de investigação o emprego, a renda e a educação. A região Centro-Oeste, por sua vez, abarcou $4,6 \%$ das pesquisas, o menor percentual entre a 
amostra selecionada. Os principais enfoques foram renda e desempenho educacional.

Apesar das pesquisas estarem voltadas a aspectos comuns, como renda e cidadania, devido as dimensões continentais do Brasil, observa-se que a noção de pobreza se diferencia e assume contornos particulares em cada região. Segundo Rocha (2006), em um país de diferenças regionais tão marcantes como o Brasil, a simples utilização do salário mínimo como parâmetro para definir a linha de pobreza não retrata a realidade, porque são ignoradas outras diferenças importantes para o desenvolvimento como a urbano-rural de custo de vida para os pobres. Daí a importância de pesquisas deste tipo continuarem sendo desenvolvidas, conhecendo os alcances do Programa Bolsa Família em meio às particularidades contextuais.

\subsection{Conteúdos temático por nível acadêmico}

Refere-se ao conteúdo temático abordado nos resumos das Dissertações e Teses empíricas. O foco desta análise está nos resultados das pesquisas, sendo classificados em cinco eixos, baseados em Oliveira e cols. (2008): a) Mudanças e consequências negativas; b) Mudanças e consequências positivas; c) Sem mudanças e conseqüências significativas; d) Discussão das mudanças e conseqüências significativas; e e) Consequências positivas com ressalvas negativas.

a) Mudanças e consequências negativas: Correspondem aos trabalhos que apontaram os prejuízos e as desvantagens relacionadas ao Programa Bolsa Família, questionando sua função de combate à pobreza. Por exemplo, o desconhecimento, por parte dos gestores, dos procedimentos de execução do Programa Bolsa Família (FREITAG, 2007); fragilidade e precariedade no acesso à rede de serviços voltados à saúde, educação e assistência social (SANTANA, 2009); e insatisfação dos usuários quanto aos serviços (RIBEIRO, 2007).

b) Mudanças e consequências positivas: Diz respeito aos resumos que destacaram as oportunidades e contribuições do Programa Bolsa Família para os beneficiários. Como exemplo, cita-se a melhora das condições de vida (REIS, 2009); crescimento econômico (VIEIRA, 2009); e fator na proteção contra a anemia e desnutrição (OLIVEIRA, 2009).

c) Sem mudanças e conseqüências significativas: refere-se aos resumos que relatam não haver diferenciação ou impactos do Programa sobre a amostra pesquisada. Por exemplo: não há impacto do PBF no rendimento escolar (ALVES, 2008); não há diferença na probabilidade de participação no mercado de trabalho (MACIEL, 2008); e ausência de impacto do programa sobre a fecundidade (procriação) dos beneficiários (ROCHA, 2009). 
d) Discussão das mudanças e conseqüências significativas: inclui trabalhos que não apresentam a direção positiva ou negativa do Programa Bolsa Família, não apresentando, portanto, resultados conclusivos. Por exemplo, a decisão da família de inserir suas crianças no mercado de trabalho (TEIXEIRA, 2009); as relações de ocupação e renda no espaço rural (OLIVEIRA, 2007); e pobreza e a exclusão social sendo enfrentadas mediante um conjunto de medidas articuladas (CARNEI RO, 2008).

e) Consequências positivas com ressalvas negativas: abrangem pesquisas que apontam vantagens do Programa Bolsa Família, ao mesmo tempo que apresentam dificuldades e impedimentos que limitam os benefícios. Por exemplo, os avanços no cumprimento das condicionalidades vis-à-vis a fragilidade e precariedade no acesso à rede de serviços saúde, educação e assistência social (SANTANA, 2009); o Bolsa Família é visto como ineficiente, mas desempenha um papel de mitigar os efeitos perversos da mecanização agrícola (OLIVEIRA, 2008); significativa permanência na escola por parte dos alunos beneficiários do Programa Bolsa Família, embora os níveis de freqüência ainda permaneçam baixos (CORRÊA, 2008).

A tabela 2 mostra a frequência e percentuais do conteúdo temático por nível acadêmico, evidenciando uma predominância $(33,6 \%)$ de pesquisas que não apontavam efeitos positivos ou negativos conclusivos do Programa Bolsa Família. Há um valor aproximado entre as pesquisas que tiveram como resultados consequências negativas, positivas e consequências positivas com ressalvas negativas $(19,5 \%, 20,4 \%$ e $19,5 \%$, respectivamente). O menor percentual $(7,1 \%)$ esteve relacionado aos conteúdos sem mudanças e consequências significativas.

Tabela 2

Frequência e percentuais do conteúdo temático por nível

Mestrado Doutorado Profissionalizante Total

\begin{tabular}{llllclcll}
\hline & $\mathrm{f}$ & $\%$ & $\mathrm{f}$ & $\%$ & $\mathrm{f}$ & $\%$ & $\mathrm{f}$ & $\%$ \\
-Consequências negativas & 17 & 19.3 & 3 & 17,6 & 2 & 25 & 22 & 19,5 \\
- Consequências positivas & 16 & 18.2 & 4 & 23,5 & 3 & 37,5 & 23 & 20,4 \\
$\begin{array}{l}\text {-Sem mudanças e } \\
\text { conseqüências significativas }\end{array}$ & 6 & 6.8 & 2 & 11,8 & 0 & 0 & 8 & 7,1 \\
$\begin{array}{l}\text {-Discussão das mudanças e } \\
\text { consequências significativas }\end{array}$ & 28 & 31.8 & 7 & 41,1 & 3 & 37,5 & 38 & 33,6 \\
-Consequências positivas & 21 & 23.9 & 1 & 5,9 & 0 & 0 & 22 & 19,5 \\
\hline com ressalvas negativas & & & & & & & &
\end{tabular}




\begin{tabular}{lllllllll}
\hline Total & 88 & 100 & 17 & 100 & 8 & 100 & 113 & 100 \\
\hline
\end{tabular}

A análise dos conteúdos temáticos por nível demonstra que, no Mestrado acadêmico e no Doutorado, os trabalhos apresentaram predominantemente conteúdo de discussão das mudanças e consequências significativas ( $31.8 \%$ e $41,1 \%$, respectivamente). Os trabalhos de Mestrado profissionalizante evidenciaram a mesma proporção $(37,5 \%)$ entre os conteúdos com consequências positivas e os de discussão das mudanças e conseqüências significativas.

Ao investigar os conteúdos dos trabalhos observou-se que não há um consenso na literatura sobre as contribuições do Programa Bolsa Família no combate à pobreza. O que predomina é uma intensa discussão a respeito do tema, apontando uma diversidade de resultados inconclusivos. Talvez devido ao curto período de implementação, ainda esteja cedo para avaliar impactos e conseqüências significativos na população brasileira.

Diversos pesquisadores, no entanto, possuem o consenso de que as estratégias de combate à pobreza consideradas de curto prazo foram alcançadas (SOARES, RIBAS \& OSÓRIO, 2007; SOARES, SOARES, MEDEIROS \& OSÓRIO, 2006). Segundo estes autores, o valor monetário pago pelo programa contribuiu de maneira substantiva para a queda da desigualdade e da redução da pobreza no país nos últimos anos, fazendo com que milhões de pessoas pudessem ter rendimentos mínimos que permitissem a elas garantir a sua sobrevivência. Por outro lado, as estratégias de médio e longo prazo merecem reflexões mais apuradas (PIRES, 2008), o que talvez esteja, entre outros, na dependência do fator tempo para que haja um consenso sobre as contribuições do PBF no combate à pobreza.

\section{Considerações finais}

O levantamento das Dissertações e Teses sobre o Programa Bolsa Família permitiu traçar um panorama das principais características das pesquisas realizadas sobre o tema no Banco de Teses da Capes. Além disso, foi possível verificar o que as publicações trazem a respeito da consolidação do programa como estratégia de combate à pobreza.

Percebeu-se que desde a sua implementação, o Programa Bolsa Família tem sido alvo de crescente interesse por parte dos pesquisadores. Os anos de 2007 e 2008 foi o período de maior condensamento de pesquisas, com prevalência das realizadas em nível de Mestrado acadêmico. O envolvimento de diversas áreas de Conhecimento foi evidenciado, revelando que a simples investigação do aumento de renda familiar não se esgota no conhecimento de um 
programa que se propõe movimentar a economia e trabalhar na perspectiva da redução dos índices de miséria e indigência.

Talvez por envolver muitas áreas de Conhecimento, os resumos das Dissertações e Teses submetidas à caracterização evidenciaram diferenças de critérios metodológicos adotados, dificultando 0 processo de sistematização desta revisão. A diversidade de normas e o baixo rigor metodológico identificado nos resumos dos estudos também interferiram negativamente neste processo.

Quanto à análise do método científico, verificou-se que a maioria das pesquisas investigadas foi conduzida sob o enfoque empírico, adotando especialmente a abordagem qualitativa. Os documentos oficiais e as famílias foram as principais amostras encontradas. Quanto ao foco de investigação nas regiões do Brasil, verificou-se que o Nordeste foi a região que mais motivou pesquisas, cujos alvos de investigação envolviam, dentre outros, o emprego, a renda e cidadania.

Em relação ao conteúdo temático das publicações houve a predominância de pesquisas que não apontavam efeitos positivos ou negativos conclusivos a respeito das contribuições do Programa Bolsa Família no combate à pobreza. Há, no entanto, um esforço por parte dos pesquisadores no sentido de refletir e aprofundar a discussão sobre o tema.

De fato, as estratégias de combate à pobreza consideradas de curto prazo, que correspondem à transferência direta de renda aos mais pobres, foram indubitavelmente alcançadas. Dessa forma, muitas famílias em situação de vulnerabilidade puderam ter suas necessidades mais pontuais amenizadas, favorecendo, em especial, aspectos relacionados à sobrevivência, como acesso a alimentação, vestuário e remédios (FREIRE, SILVA, MOURA, PONTES \& BORGES, 2013).

Porém as estratégias de médio e longo prazos necessitam ser aprofundadas, como àquelas referentes ao fortalecimento do direito de acesso das famílias pobres aos serviços de educação e saúde, além daquelas que promovem a integração entre o Bolsa Família e as outras políticas públicas. Isso se justifica, segundo Scheeffer e Johnson (2008), pela análise de que apesar dos incontestáveis avanços do PBF, muitos são seus limites: baixos valores da prestação; rigorosos critérios de acesso; e implementação ainda não acompanhada de um forte aparato político pedagógico de emancipação, entre outros. Com a melhoria destas e de outras questões, talvez, será possível afirmar com precisão se o PBF tem atuado eficazmente no combate a pobreza no Brasil.

Assim, ao mapear Dissertações e Teses sobre o Programa Bolsa Família, esta pesquisa buscou contribuir com o processo construtivo de Conhecimento das diversas áreas que tomam este programa como objeto de estudo. Sugere-se mapear outras bases de dados e 
revistas, para que o Conhecimento da produção científica tenha um avanço, servindo de possível suporte para avaliação do programa e seu aperfeiçoamento como estratégia de combate à pobreza.

\section{Referências}

ALVES, E. O. Programa bolsa família: uma avaliação do impacto no rendimento escolar das crianças de famílias beneficiadas pelo Programa. 2008. 258f. Dissertação (Mestrado em Psicologia) Universidade Federal da Paraíba-UFPB, J oão Pessoa, 2008.

BARRETO, A. C., BUCHER-MALUSCHKE, J. S. N. F., ALMEIDA, P. C.; DESOUZA, E. Desenvolvimento humano e violência de gênero: uma integração bioecológica. Psicologia: Reflexão e Crítica, Porto Alegre, v. 22, n. 1, p. 86-92, 2009.

BRANDAU, R.; MONTEIRO, R., BRAILE, D. M. Importância do uso correto dos descritores nos artigos científicos. Revista brasileira de cirurgia cardiovascular. São José do Rio Preto, v. 20, n. 1, 2005.

BRONFENBRENNER, U. A ecologia do desenvolvimento humano: experimentos naturais e planejados. Porto Alegre: Artes Médicas, 1996.

BURLANDY, M. C. M. S.; MONNERAT, G. L.; SCHOTTZ, V.; MAGALHÃES, R. Programa Bolsa Família: nova institucionalidade no campo da política social brasileira. Revista Katáysis, Florianópolis, vol. 10, n. 1, p. 86-94, 2007.

CAIXA ECONÔMICA FEDERAL. Disponível em <http://www.caixa.gov.br/voce/social/transferencia/bolsa_familia/ind ex.asp>. Acesso em: 23 maio 2011.

CAMPOMAR, M. C. Do uso de "estudo de caso" em pesquisa para Dissertações e Teses em Administração. Revista de Administração, São Paulo, v. 26, n. 3, p. 95-97, 1995.

CANEN, A.; ARBACHE, A. P.; FRANCO, M. Pesquisando multiculturalismo e educação: o que dizem as Dissertações e Teses. Educação \& Realidade. Porto Alegre, v. 26, n. 1, p. 161-181, 2001. CARNEIRO, M. P. A. K. B. A Percepção das mulheres beneficiárias sobre a implementação do programa bolsa família em Viçosa-MG. 2008. 215f. Dissertação. (Mestrado em Economia Doméstica) - Universidade Federal de Viçosa-UFV/MG, Viçosa, 2008.

CECCONELLO, A. M.; KOLLER, S. H. M. Inserção ecológica na comunidade: uma proposta metodológica para o estudo de famílias em situação de risco. Psicologia Reflexão e Crítica, Porto Alegre, vol. 16, n.3, p. 515-524, 2003.

COOK, D. J.; MULROW C. D.; HAYNES, R. B. Systematic reviews: synthesis of best evidence for clinical decisions. Annals of I nternal Medicine, cidade, v. 126, n. 5, p. 376-380, 1997. 
CORRÊA, J. S. O Programa bolsa família como alternativa de inclusão e permanência na escola. 2008. 94f. Dissertação (Mestrado em Educação) - Universidade Federal de Santa MariaUFSM/RS, Santa Maria, 2008.

FERREIRA, N. V. T. Programa bolsa família: o velho com novas roupagens. Argumentum, Vitória, v. 2, n. 1, p. 232, 2010.

FREIRE, V. R. B. P.; SILVA, S. S. C.; MOURA, M. L. S.; PONTES, F. A. R. \& BORGES, J. A. R. Atividades acadêmicas e a rotina de crianças ribeirinhas participantes do Programa Bolsa Família. Psicologia: teoria e Pesquisa, v. 29, n. 2, p. 159-166, 2013.

FREITAG, A. O Programa "Fome Zero" na região das missões: a política social de combate à pobreza pela redistribuição de renda. 2007. 160f. Dissertação (Mestrado em Ciências Sociais) Universidade do Vale do Rio dos Sinos-Unisinos/RS, São Leopoldo, 2007.

INSTITUTO BRASILEIRO DE GEOGRAFIA E ESTATÍSTICA [IBGE]. Síntese de indicadores sociais. 2008. Rio de Janeiro: Instituto Brasileiro de Geografia e Estatística, 2009.

INSTITUTO DE PESQUISA ECONÔMICA APLICADA (IPEA). I peadata, Banco de dados macroeconômicos, sociais e regionais do Brasil. 2007. Disponível em: <http://www.ipeadata.gov.br>. Acesso em 16 maio 2010.

KERSTENETZKY, C. L. Redistribuição e Desenvolvimento? A Economia Política do Programa Bolsa Família. DADOS, Rio de Janeiro, vol. 52, n. 1, p. 53-83, 2009.

OLIVEIRA, V. D. As tecnologias e suas interfaces no campo com estratégia de controle do capital. 2007. 158f. Dissertação (Mestrado em Geografia) - Fundação Universidade Federal de Sergipe-UFS, São Cristóvão, 2007.

LOPES, A. L. M.; FRACOLLI, L. A. Revisão sistemática de literatura e metassíntese qualitativa: considerações sobre sua aplicação na pesquisa em enfermagem. Texto \& Contexto Enfermagem, Florianópolis, vol. 17, n.4, p. 771-778, 2008.

LOURENÇO, G. M. A orientação econômica no segundo mandato. Análise Conjuntural, cidade, v. 28, n. 2, p. 11-12, 2006.

$\mathrm{MACI} E \mathrm{~L}, \mathrm{M}$. C. A Divisão do trabalho doméstico e a oferta de trabalho dos casais no Brasil. 2008. 126f. Dissertação( Mestrado em Economia) - Universidade Federal de Pernambuco-UFPE, Recife, 2008.

MATHEUS, M. C. C. Metassíntese qualitativa: desenvolvimento e contribuições para a prática baseada em evidências. Acta Paulista de Enfermagem, São Paulo, v. 22, n. spe1, p. 543-5, 2009.

MEDEIROS, M.; BRITTO, T.; SOARES, F. Programas focalizados de transferência de renda no Brasil: contribuições para o debate. Brasília. (Texto para discussão, 1283), 2007. 
MINISTÉRIO DO DESENVOLVIMENTO SOCIAL E COMBATE À FOME [MDS]. 2010. Disponível em <http://www.fomezero.gov.br/noticias/arquivos/perfil_pbf_2009.ppt/ download>. Acesso em 07 maio 2010.

OLIVEIRA, D.; SIQUEIRA, A. C.; DELL'AGLIO, D. D.; LOPES, R. C. S. Impacto das Configurações Familiares no Desenvolvimento de Crianças e Adolescentes: Uma revisão da produção científica. I nteração em Psicologia, Porto Alegre, 12 (1), p. 87-98, 2008.

OLIVEIRA, D. C. Elite do agronegócio em Unaí: percepções sobre pobreza e desigualdades Sociais. 2008. 120f. Dissertação (Mestrado em Sociologia) - Universidade Federal Rural do Rio de Janeiro-UFRRJ, Rio de Janeiro, 2008.

OLIVEIRA, F. C. C. Estado nutricional de crianças cadastradas no programa bolsa família do município de Paula Cândido, MG: ênfase em déficit estatural e anemia ferropriva. 2009. $167 \mathrm{f}$. Dissertação (Mestrado em Nutrição) - Universidade Federal De Viçosa-UFV, Viçosa, 2009.

OLIVEIRA, J. A. P. Desafios do planejamento em políticas públicas: diferentes visões e práticas, Revista Administração Pública, Rio de Janeiro, vol. 40, n. 2, jul./dez. 2006.

PIRES, A. Bolsa Família e políticas públicas universalizantes: o caso de um município paulista. Caderno de Pesquisa, São Paulo, v. 38, n. 134, ago, 2008.

PLANO DE GOVERNO 2007/2010. Lula Presidente. Disponível em <htttp://www.pt.org.br/portalpt/dowload. php.file=dados/bancoimg/c 091003193431plano-governo.pdf>. Acesso em: 09 mar 2010.

REIS, A. C. E. Bolsa Família: uma análise dos resultados sob a óptica educacional. 2009. 97f. Dissertação (Mestrado em Educação) - Universidade Estadual Paulista Júlio De Mesquita FilhoUnesp/SP, Marília, 2009.

REIS, E.; SHWARTZMAN, S. Pobreza e Exclusão Social: Aspectos Sócio-Políticos. In: As causas da pobreza no Rio de Janeiro. Editora da FGV, 2004.

RIBEIRO, E. A. Significados da Pobreza, assistência social e cidadania: reflexões a partir da fala dos usuários do projeto de criação de galinha caipira em Redenção-CE. 2007. 100f. Dissertação (Mestrado em Políticas públicas e Sociedade) - Universidade Estadual do Ceará-UECE, Fortaleza, 2007.

ROCHA, R. C. B. Três ensaios em avaliação de intervenções sociais com foco comunitário e familiar. $2009.94 \mathrm{f}$. Dissertação(Mestrado em Economia) - Pontifícia Universidade Católica do Rio de Janeiro, Rio de Janeiro, 2009.

ROCHA, S. Pobreza no Brasil: afinal, de que se trata? 3. ed. Rio de Janeiro: Editora FGV, 2006.

SANTANA, C. S. Programa Bolsa Família em Duque de Caxias / RJ : desafios do processo de implementação. 2009. 147f. Dissertação 
(Mestrado em Saúde Coletiva) - Fundação Oswaldo Cruz-Fiocruz/RJ, Manguinhos, 2009.

SCHEEFFER, F.; JOHNSON, G. A. As diretrizes do Programa Bolsa Família: uma análise crítica. Revista Avaliação de Políticas Públicas, Fortaleza, CE, v. 2, n. 2, p. 7- 17, jul./dez. 2008.

SIQUEIRA, A. C.; DELL'AGLIO, D. D. Retornando à família de origem: Fatores de risco e proteção no processo de reinserção familiar de uma adolescente institucionalizada. Revista Brasileira de Crescimento e Desenvolvimento Humano, São Paulo, vol. 17, n. 2, p. 134-146, 2007.

SOARES, F. V.; SOARES, S.; MEDEIROS M.; OSÓRIO, R. G. Programas de transferência de renda no Brasil: impactos sobre a desigualdade. Rio de Janeiro: I pea, out. 2006. (Texto para discussão, 1228).

em:

<http://www.ipea.gov.br/sites/000/2/publicacoes/tds/td_1228.pdf>.

Acesso em: 14 ago 2010.

SOARES, F. V.; RIBAS, R. P.; OSÓRIO, R. G. Evaluating the impact of Brazil's Bolsa Família: cash transfer programmes in comparative perspective. PNUD, International Poverty Center. 2007. Disponível em: $\quad<$ http://www.ipc-undp.org/pub/l PCEvaluationNote1.pdf>. Acesso em: 26 out 2010.

TEIXEIRA, A. C. M. O impacto do Programa bolsa família sobre o trabalho infantil na região Nordeste do Brasil. 2009. 58f. Dissertação(Mestrado em Economia) - Universidade Estadual do Ceará-Uece, Fortaleza, 2009.

THORNE, S.; JENSEN, L.; KEARNEY, M. H.; NOBLIT, G.; SANDELOWSKI, M. Qualitative methasynthesis: reflections on methodological orientation and ideological agenda. Qualitative Health Research, Vancouver, v. 14, n. 10, p. 1342-65. Review, 2004

VIEIRA, E. A. Desigualdade e pobreza em perspectiva: caso de Mato Grosso. 2009. 136f. Dissertação (Mestrado em Agronegócios e Desenvolvimento Regional) - Universidade Federal De Mato GrossoUFMT, Cuiabá, 2009.

ZIMMERMANN, C. R. Os programas sociais sob a ótica dos Direitos humanos: o caso do Bolsa Família do Governo Lula no Brasil. Revista internacional de direitos humanos, São Paulo, n. 4, ano 3, 2006.

\section{Endereço para correspondência}

Viviam Rafaela Barbosa Pinheiro Freire

Universidade Federal do Pará, Núcleo de Teoria e Pesquisa do Comportamento, Laboratório de Ecologia do Desenvolvimento. Rua Augusto Corrêa, 01 - Guamá, CEP 66075-110, Belém, PA, Brasil.

Endereço eletrônico: viviamrafaela@hotmail.com

Simone Souza da Costa Silva 
Viviam Rafaela Barbosa Pinheiro Freire, Simone Souza da Costa Silva,

Lilia Iêda Chaves Cavalcante, Fernando Augusto Ramos Pontes

Programa Bolsa Família como estratégia de combate à pobreza em

Dissertações e Teses no Brasil

Universidade Federal do Pará, Núcleo de Teoria e Pesquisa do Comportamento, Laboratório de Ecologia do Desenvolvimento. Rua Augusto Corrêa, 01 - Guamá, CEP 66075-110, Belém, PA, Brasil.

Endereço eletrônico: symonufpa@gmail.com

\section{Lilia I êda Chaves Cavalcante}

Universidade Federal do Pará, Núcleo de Teoria e Pesquisa do Comportamento, Laboratório de Ecologia do Desenvolvimento. Rua Augusto Corrêa, 01 - Guamá, CEP 66075-110, Belém, PA, Brasil.

Endereço eletrônico: liliaccavalcante@gmail.com

\section{Fernando Augusto Ramos Pontes}

Universidade Federal do Pará, Núcleo de Teoria e Pesquisa do Comportamento, Laboratório de Ecologia do Desenvolvimento. Rua Augusto Corrêa, 01 - Guamá, CEP 66075-110, Belém, PA, Brasil.

Endereço eletrônico: fernando.pontes@pq.cnpq.br

Recebido em: 23/08/2011

Reformulado em: 15/08/2012

Aceito para publicação em: 29/09/2012

Acompanhamento do processo editorial: Ana Maria Lopez Calvo de Feijoo

\section{Notas}

${ }^{1}$ Pesquisa financiada pelo CNPQ.

* Terapeuta Ocupacional, Mestre em Teoria e Pesquisa do comportamento Universidade Federal do Pará, Brasil.

** Professora vinculada ao Núcleo de Teoria e Pesquisa do Comportamento Universidade Federal do Pará, Brasil.

*** Professora vinculada ao Instituto de Ciências Sociais Aplicadas e ao Programa de Pós-Graduação em Teoria e Pesquisa do Comportamento - Universidade Federal do Pará, Brasil.

**** Professor vinculado ao Núcleo de Teoria e Pesquisa do Comportamento Universidade Federal do Pará, Brasil. Bolsista de Produtividade em pesquisas CNPQ. 